\title{
Does plant immunity play a critical role during initiation of the legume-rhizobium symbiosis?
}

\author{
Katalin Tóth and Gary Stacey* \\ Division of Plant Sciences and Biochemistry, Christopher S. Bond Life Sciences Center, National Center for Soybean \\ Biotechnology, University of Missouri-Columbia, Columbia, MO, USA
}

\section{OPEN ACCESS}

Edited by:

Etienne Yergeau,

National Research Council Canada,

Canada

Reviewed by:

Robin Katrina Cameron, McMaster University, Canada

Christian Staehelin,

Sun Yat-sen University, China

*Correspondence: Gary Stacey,

Division of Plant Sciences and Biochemistry, Christopher S. Bond Life Sciences Center,

National Center for Soybean

Biotechnology, University of Missouri-Columbia, Columbia,

MO 65211, USA

staceyg@missouri.edu

Specialty section:

This article was submitted to Plant-Microbe Interaction,

a section of the journal

Frontiers in Plant Science

Received: 03 April 2015 Accepted: 19 May 2015

Published: 02 June 2015

Citation:

Tóth K and Stacey G (2015) Does plant immunity play a critical role during initiation of the legume-rhizobium symbiosis? Front. Plant Sci. 6:401. doi: 10.3389/fpls.2015.00401
Plants are exposed to many different microbes in their habitats. These microbes may be benign or pathogenic, but in some cases they are beneficial for the host. The rhizosphere provides an especially rich palette for colonization by beneficial (associative and symbiotic) microorganisms, which raises the question as to how roots can distinguish such 'friends' from possible 'foes' (i.e., pathogens). Plants possess an innate immune system that can recognize pathogens, through an arsenal of protein receptors, including receptor-like kinases (RLKs) and receptor-like proteins (RLPS) located the plasma membrane. In addition, the plant host has intracellular receptors (so called NBS-LRR proteins or $\mathrm{R}$ proteins) that directly or indirectly recognize molecules released by microbes into the plant cell. A successful cooperation between legume plants and rhizobia leads to beneficial symbiotic interaction. The key rhizobial, symbiotic signaling molecules [lipo-chitooligosaccharide Nod factors (NF)] are perceived by the host legume plant using lysin motif-domain containing RLKs. Perception of the symbiotic NFs trigger signaling cascades leading to bacterial infection and accommodation of the symbiont in a newly formed root organ, the nodule, resulting in a nitrogen-fixing root nodule symbiosis. The net result of this symbiosis is the intracellular colonization of the plant with thousands of bacteria; a process that seems to occur in spite of the immune ability of plants to prevent pathogen infection. In this review, we discuss the potential of the invading rhizobial symbiont to actively avoid this innate immune response, as well as specific examples of where the plant immune response may modulate rhizobial infection and host range.

Keywords: legume, root nodule symbiosis, plant immunity, receptor-like kinase, nod factor, lipo-polysaccharides

\section{Introduction}

The root nodule symbiosis (RNS) is one of the most fascinating, yet not completely understood beneficial host-microbe interactions. RNS is limited to the FaFaCuRo (Fabales, Fagales, Cucurbitales, and Rosales) clade that belongs to Eurosid I plants (Kistner and Parniske, 2002). Under nitrogen limiting conditions, many legume plants are infected by nitrogen-fixing soil bacteria, termed rhizobia. Subsequent to an initial signal exchange between host and symbiont, the bacteria enter the host root usually through epidermal root hair cells. An infection thread (IT) of plant origin is formed that extends and eventually delivers the rhizobia into newly dividing cortical cells. These cells give rise to a nodule primordium that develops into the nodule, a new root organ. In the 
nodule, bacteria differentiate into bacteroids, the nitrogen-fixing form of rhizobia, which reduces atmospheric dinitrogen into ammonia that is used by the host plant. In exchange, the bacteria receive a steady carbon source provided by plant photosynthesis.

Although the first observation of legume nodulation was reported a few 100 years ago, we still do not fully understand the underlying mechanisms that maintain a perfect balance between host and symbiont to allow such an intimate symbiosis to develop. Among the exciting new findings is a growing recognition that the plant immune system is active during RNS. In this review, we will point out recent observations to indicate when and how the host plant immune system acts to control nodule formation and host range.

\section{Rhizobia are Part of a Diverse and Active Rhizosphere Microbiota}

In the soil, there is an extremely large population of microorganisms that keep the soil ecosystem functioning. For instance, a metagenomics study of the Arabidopsis thaliana rhizosphere revealed 43 bacterial phyla and divisions (Bulgarelli et al., 2012). Microorganisms of the rhizosphere (part of the soil directly surrounding and impacted by the root) interact with the roots, providing nutrients and protection against biotic and abiotic stress. Specific rhizosphere microbes also have the ability to enter the root and become inter- or intracellular inhabitants, sometimes contributing to plant growth and development (Bulgarelli et al., 2012; Lundberg et al., 2012). Given the diversity of rhizosphere microbes and the potential threat for the plant, it is not surprising that plants have the ability to distinguish threatening intruders (i.e., pathogens) from beneficial microbiota.

Hundreds of different microorganisms are attached to the surface of a root. Leguminous plants under nitrogen limiting conditions secrete secondary metabolites (e.g., flavonoids) that can signal to and recruit compatible, symbiotic rhizobia (Oldroyd et al., 2011). Specific flavonoids act as inducers of the rhizobial nodulation genes, which encode the enzymes needed for synthesis of the lipo-chitooligosaccharide (LCO) nodulation factor [Nod factors (NF)], the key rhizobial signaling molecule that elicits the first plant responses in establishing RNS (Fisher and Long, 1992).

\section{Parallels between Symbiont- and Pathogen-Triggered Responses}

The term 'microbe-associated molecular pattern' (MAMP) is used for specific recognition signatures found in conserved molecules [e.g., bacterial flagellin, cell wall components like lipopolysaccharide, chitin and peptidoglycan (PGN)] derived from microbes, usually pathogens that infect both plants and animals (Ausubel, 2005). MAMPs are characterized by their ability to induce an innate immune response in the host. Therefore, NF is usually not considered a MAMP since it induces nodule formation on the host, as opposed to inducing immunity. However, NF can induce some responses that are normally associated with plant innate immunity (Day et al., 2001; Ramu et al., 2002; Pauly et al., 2006). This is perhaps not surprising since longer chain chitin oligomers (degree of polymerization $>6$ ) are strong inducers of plant innate immunity (Liang et al., 2014). Unlike simple chitin, NF is a LCO molecule comprised of an $\mathrm{N}$-acetylglucosamine backbone with site-specific decorations and an $\mathrm{N}$-acyl chain (D'Haeze and Holsters, 2002). The addition of very low concentrations of $\mathrm{NF}(<10 \mathrm{nM})$ was shown to induce a variety of responses on the compatible legume hosts. These include plasma membrane depolarization, perinuclear calcium spiking, cytoskeletal changes, root hair deformation, induction and repression of gene expression and, in a few plant species, induction of nodule primordia (D'Haeze and Holsters, 2002; Oldroyd and Downie, 2008).

Responses elicited by MAMP perception have been wellstudied in many plants (De Coninck et al., 2015). These include generation of reactive oxygen species (ROS), cytosolic $\mathrm{Ca}^{2+}$ elevations, activation of mitogen-activated protein kinase (MAPK) and calcium-dependent kinases, callose deposition and defense-related gene expression (Boller and Felix, 2009; Greeff et al., 2012). However, in comparison with leaves, less attention has been paid to MAMP responses in roots even though many pathogens do invade via roots. MAMPtriggered immune signaling in Arabidopsis roots occurs in a similar fashion to leaves (Millet et al., 2010; De Coninck et al., 2015). Roots of seedlings responded by callose deposition to MAMPs like flg22 (a peptide molecule originating from bacterial flagellin), PGN and chitin. Callose deposition was observed in the root elongation zone in response to flg22 and PGN, while chitin elicited callose deposition in the root maturation zone (Millet et al., 2010), indicating the ability of different root tissues to distinguish between these MAMPs (De Coninck et al., 2015).

\section{Receptor-Like Kinases Involved in Symbiotic and/or Immune Signaling}

Microbe-associated molecular patterns are recognized by pattern recognition receptors (PRRs) localized at the cell surface, including receptor-like kinases (RLK) and receptor-like proteins (Zipfel, 2014). The extracellular region of RLKs can be composed of lysin motif (LysM)-domains (LysM-RLK) and/or leucinerich repeats (LRR-RLK), both of which are involved in microbe detection (Greeff et al., 2012).

NF is perceived by RLKs with an extracellular domain of 23 LysM domains, a single membrane-spanning region and an active or inactive intracellular kinase domain. These LysM-RLKs were identified in model legume species such as LjNFR1/LjNFR5 (NF Receptor 1 and 5) in Lotus japonicus, GmNFR1/GmNFR5 in soybean (Glycine max), and LYK3/NFP [Lysin motif receptorlike kinase 3 and NF Perception (NFP)] in Medicago truncatula (Amor et al., 2003; Limpens et al., 2003; Madsen et al., 2003; Radutoiu et al., 2003; Indrasumunar et al., 2010, 2011). Mutations in these genes significantly alter nodulation capability of the legume host.

The data suggest that the NF receptor is composed of a heterodimer or, perhaps, heterotetramer. LjNFR5 binds NF with higher affinity than LjNFR1 (Broghammer et al., 2012). However, LjNFR5 or MtNFP lack kinase activity (Arrighi et al., 2006; Madsen et al., 2011) and, therefore, likely signal by activation of the NFR1 or LYK3, respectively, kinase domain. Co-expression 
of LjNFR1 and LjNFR5, as well as MtNFP and MtLYK3, in a heterologous in planta tobacco system induced strong defense responses in the absence of NF (Madsen et al., 2011; Pietraszewska-Bogiel et al., 2013). These responses were similar to those elicited by over-expression of CERK1 in Arabidopsis, another LysM-RLK. AtCERK1 has an active intracellular kinase domain and functions as a heterotetramer with AtLYK5, which lacks a functional kinase domain, to recognize long-chain chitooligosaccharides $(\mathrm{dp}>6)$ to induce plant immune responses (Cao et al., 2014; Liang et al., 2014).

Recently, it was shown that the rice MAMP receptor OsCERK1, is also required for establishment of symbiosis with mycorrhizal fungi (Miyata et al., 2014; Zhang et al., 2015). Similar to rhizobia, establishment of this symbiosis also involves a LCO signal, called Myc factor, as well as shortchain chitooligosaccharides ( $\mathrm{dp}<6$; Maillet et al., 2011; Genre et al., 2013). OsCERK1 displays the highest homology with LjNFR1. Therefore, a possible role of LjNFR1 and MtLYK3 in mycorrhization was tested with the results implicating both in the establishment of this symbiosis (Zhang et al., 2015). In M. truncatula, MtNFP was shown to be involved in the response to root oomycete pathogen Aphanomyces euteiches, $n f p$ mutant plants were more susceptible to the oomycete than wild type plants (Rey et al., 2013). Indeed, recently, mutations in a number of $M$. truncatula symbiotic genes were shown to affect the ability of Phytophtora palmivora to infect roots; again emphasizing the overlap between symbiont and pathogen response (Rey et al., 2015).

Taken together, the data support the hypothesis that chitin and LCO reception are functionally related with the latter likely evolving from the more wide-spread and ancient chitin recognition system (Liang et al., 2014). The fact that, in some species, CERK1 and its orthologs function both in pathogen and symbiont recognition argue that this step may not be involved in discerning the beneficial or detrimental nature of the infecting microbe. This is a rather heretical view given the dogma from earlier studies that argued that LCO reception plays a key role in host range determination (Oldroyd et al., 2011).

\section{Do Rhizobia Suppress the Plant Immune System?}

The question whether the plant immune system might be involved in RNS is an obvious one considering the intimacy of the RNS (Fisher and Long, 1992). Unfortunately, this question has not received a great deal of direct, experimental examination. However, there are a number of observations that are consistent with a rapid, defense-like response occurring in legumes when infected by rhizobia (Figure 1). For instance, strong production of ROS was observed on alfalfa roots in response to the compatible symbiont Sinorhizobium meliloti (Santos et al., 2001). Transient and rapidly elevated ROS levels were observed on common bean Phaseolus vulgaris root hairs upon NF addition at physiological concentration $\left(10^{-9} \mathrm{M}\right.$; Cardenas et al., 2008). Silencing of NADPH oxidase, required for ROS production, resulted in aborted IT formation and reduced nodule numbers on common bean roots (Montiel et al., 2012). The results suggest that ROS production is necessary for infection initiation but prolonged, elevated levels could be detrimental to nodulation.

A hypersensitive, cell death response was also reported on alfalfa roots in response to S. meliloti (Vasse et al., 1993). These results are consistent with recent large-scale transcriptomic and phosphoproteomic studies, performed on soybean and $M$. truncatula in response to their symbiotic rhizobia or purified $\mathrm{NF}$, that revealed rapid induction of defense-related gene expression, as well as phosphorylation of proteins known to be involved in plant immune responses (Libault et al., 2010; Nguyen et al., 2012; Rose et al., 2012).

The levels of salicylic acid (SA), a key secondary signal involved in plant innate immunity (An and Mou, 2011), were found to increase in alfalfa roots upon inoculation with NFdefective (nodC mutant) rhizobia (Martínez-Abarca et al., 1998). Indeed, transgenic roots in which SA levels were reduced by expression of NahG, showed increased rhizobial infection (Stacey et al., 2006). Similarly, a number of other phytohormones, also involved in plant innate immunity, can affect the RNS (e.g., jasmonic acid; Ding and Oldroyd, 2009).

If the plant does mount a defense response to invading rhizobia, then, by analogy to bacterial pathogens, it is possible that rhizobia also have the ability to actively suppress this response. Indeed, suppression of immune responses, such as ROS production and SA accumulation, was demonstrated in $M$. truncatula and $M$. sativa roots upon addition of NF (Martínez-Abarca et al., 1998; Shaw and Long, 2003). In addition, down-regulation of a PR2 (pathogenesis-related protein) homolog in $M$. truncatula was reported in response to $S$. meliloti inoculation, while a $S$. meliloti mutant defective in NF synthesis failed to induce the same response (Mitra and Long, 2004). Surprisingly, NF application can suppress defense responses not only in legumes but also non-legumes, such as Arabidopsis, tomato, and corn. For example, Arabidopsis leaves pre-treated with flg22 elicit a strong innate immune response that was suppressed by addition of NF (Liang et al., 2013). These findings suggest that LCO/NF might have a dual role in actively inducing RNS development while also actively suppressing plant immunity, which could inhibit RNS (Figure 1).

\section{Nodulation without Nod Factor Signaling Reveals a Key Role for Plant Innate Immunity in RNS}

The dogma that existed for many years in the field of RNS research is that nodulation cannot occur in the absence of NF signaling. Thus, it was quite surprising when some rhizobia were found to nodulate specific Aeschynomene species in the complete absence of the nodulation genes, required for NF synthesis (Giraud et al., 2007). More recently, Okazaki et al. (2013) showed that a nodulation defective, $n f r 1$ mutant of the soybean cultivar Enrei could be nodulated by a Bradyrhizobium elkanii mutant unable to produce NF. Even more surprising was the finding that nodulation by this mutant was dependent on an active type III secretion system (T3SS). Microarray analysis revealed that symbiosis marker genes such as ENOD40 and NIN were induced in the nfrl mutant suggesting T3SS-induced signaling 


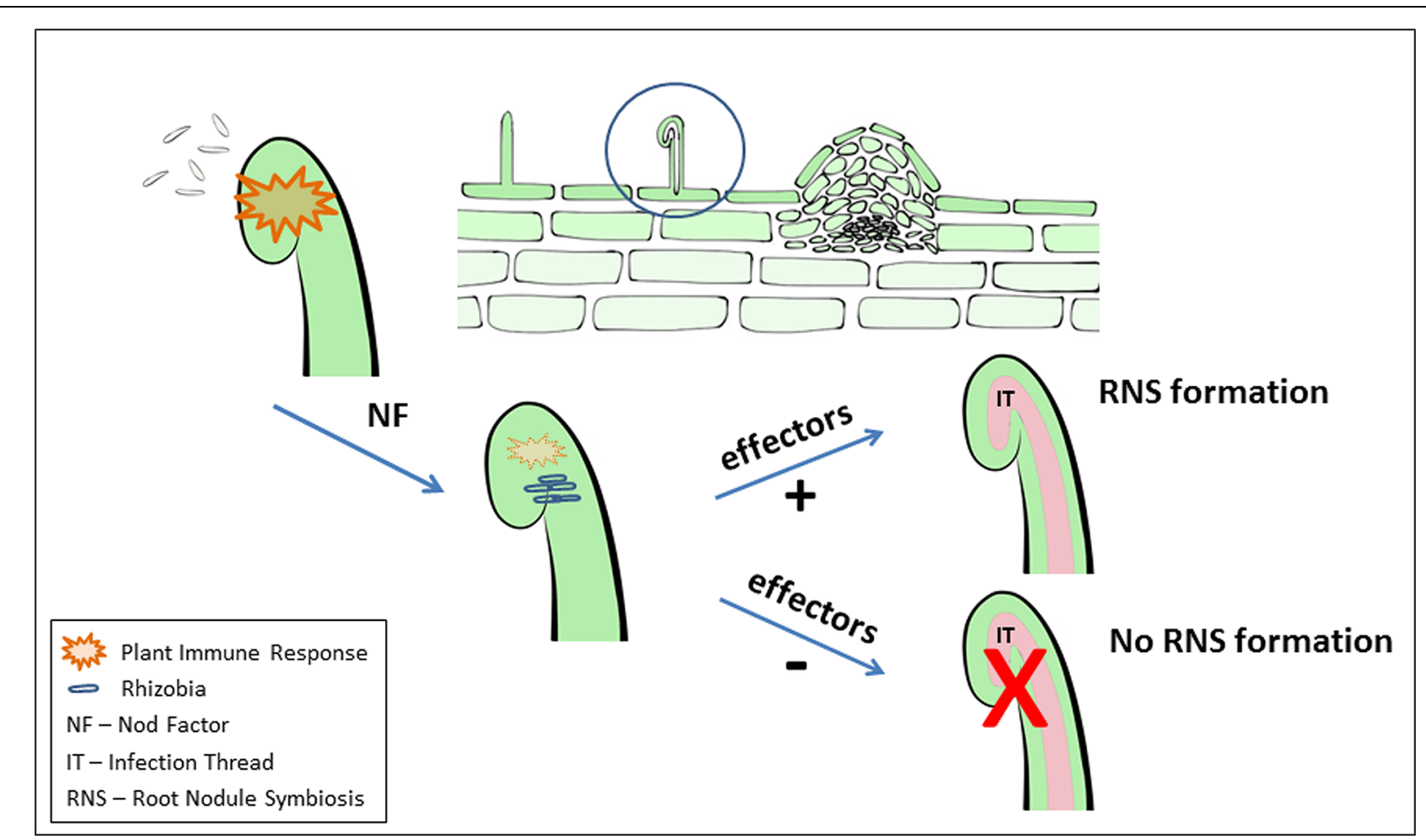

FIGURE 1 | Schematic illustration of elicitation and suppression of immune responses by Rhizobia during root nodule symbiosis (RNS) formation. As discussed in the manuscript, during the early events of initiation of the legume-rhizobia symbiosis, a plant immune response is induced (illustrated by orange). In addition to acting as a signal to induce RNS development the Nod factor signal also acts to suppress this immune response. Bacterial effector proteins (e.g., delivered through a T3SS) can act to either negatively or positively modulate RNS. Strictly for the purposes of illustration, these events are shown as acting on a single root hair. However, clearly the situation is much more complex and it is likely that the plant immune response can impact RNS at various steps during its development.
(Okazaki et al., 2013). In plant pathogens, the T3SS secretes effector proteins directly into the plant cell that can enhance infection or, when the appropriate $\mathrm{R}$ protein is present, induce effector-triggered immunity (ETI; Boller and Felix, 2009).

Effectors are directly or indirectly perceived by nucleotidebinding site-LRR (NBS-LRR) receptors encoded by $R$ (resistance)-genes (Boller and Felix, 2009). In soybean, Rj2 and $R f g 1$ alleles were found to restrict nodulation in a strainspecific manner; that is, while $R j 2$ prevents nodulation with certain $B$. japonicum strains, $R f g 1$ restricts the symbiosis with at least one $S$. fredii strain (i.e., USDA257; Yang et al., 2010). Tsukui et al. (2013) showed that the incompatibility of B. japonicum (USDA122) with Rj2 soybean genotypes is mediated by the T3SS. This type of strain-specificity seems very analogous to the racespecificity of plant pathogens that is known to be determined by ETI. Kimbrel et al. (2013) examined Type III effector genes in S. fredii and B. japonicum and found that these genes exhibit a high degree of conservation in comparison to those secreted by pathogens.

The results of Okazaki et al. (2013) stand out since, for the first time, they suggest that the T3SS and associated effector proteins play a central role in RNS establishment. However, it remains to be determined which of the various $B$. elkanii effectors are required for nodule formation on soybean cv. Enrei. There is a wealth of earlier literature that supports a role for rhizobial effectors in modulating host range. Much of this work was done using Rhizobium sp. NGR234, which exhibits a very extended host range providing a variety of host species on which to examine nodulation (Perret et al., 2000). For example, the effector NopL from Rhizobium sp NGR234, when expressed in tobacco and L. japonicus was shown to suppress pathogen induction of PR protein expression and to interfere with MAPK signaling (Bartsev et al., 2004; Zhang et al., 2011). The dominant Rj4 allele in soybean encodes a PR protein that was found to restrict soybean nodulation with certain B. elkanii and B. japonicum strains. These strains were restricted in infection of the epidermal cell layers of wild soybean (G. soja) roots (Hayashi et al., 2014; Tang et al., 2014). Perhaps relevant to the work on soybean, the S. fredii effector NopP and the B. japonicum effectors NopE1 and NopE2 were shown to be directly transported into the host plant cells of Vigna roots (Schechter et al., 2010; Wenzel et al., 2010). Both NopE and NopT exhibit protease activity. B. japonicum effector NopT1 triggered cell death response when expressed in tobacco, while the NopT2 did not induce the same response (Dai et al., 2008; Kambara et al., 2009; Fotiadis et al., 2012). As mentioned earlier, strong ROS production was observed in response to NF application (Cardenas et al., 2008). NGR234 NopM (an E3 ubiquitin ligase) effector expressed in tobacco inhibited ROS 
production, while inducing defense-related gene expression (Xin et al., 2012).

Published data suggest that the need for an active effector secretion system (e.g., T3SS) is widespread in legumes. For example, wild type M. loti (MAFF303099) is not able to infect Leucaena leucocephala (a mimosoid tree), while the T3SS mutant was able to efficiently nodulate this same species (Hubber et al., 2004; Sánchez et al., 2009). Not all rhizobia possess a T3SS but in these cases other systems may operate. For example, $M$. loti strain R7A, S. meliloti and R. etli possess a type IV secretion system (T4SS; Soto et al., 2006). Deletion of T4SS in M. loti strain R7A extended the nodulation host range to include L. leucocephala, which is not nodulated by the wild type strain (Hubber et al., 2004). On the other hand, mutation of the T4SS in S. meliloti did not seem to impact formation of a functional symbiosis on alfalfa roots (Jones et al., 2007).

\section{Conclusion and Future Perspectives}

Some 29 years ago, our laboratory published a review that sought to compare and contrast rhizobium, agrobacterium and pathogen infection of plants (Halverson and Stacey, 1986). Therefore, it is satisfying to now see how many interesting parallels have been documented between rhizobial-plant, mycorrhizal-plant, and pathogen-plant interactions. For example, MAMP signaling and the associated receptors are clearly relevant to these associations. It is now well accepted that LCO and chitin signaling share similar receptors, reflecting an evolutionary connection. Indeed, in some cases, the chitin receptor plays a dual role in recognizing plant fungal pathogens, while also promoting symbiotic development.

When well established dogma in any field gets overturned, it means that research progress is being made. An example in the rhizobial field is the realization that nodulation does not sensu stricto require NF production. In the case of soybean, nodulation

\section{References}

Amor, B. B., Shaw, S. L., Oldroyd, G. E., Maillet, F., Penmetsa, R. V., Cook, D., et al. (2003). The NFP locus of Medicago truncatula controls an early step of Nod factor signal transduction upstream of a rapid calcium flux and root hair deformation. Plant J. 34, 495-506. doi: 10.1046/j.1365-313X.2003.01743.x

An, C., and Mou, Z. (2011). Salicylic acid and its function in plant immunity. J. Integr. Plant Biol. 53, 412-428. doi: 10.1111/j.1744-7909.2011.01043.x

Arrighi, J. F., Barre, A., Ben Amor, B., Bersoult, A., Soriano, L. C., Mirabella, R., et al. (2006). The Medicago truncatula lysin [corrected] motif-receptor-like kinase gene family includes NFP and new nodule-expressed genes. Plant Physiol. 142, 265-279. doi: 10.1104/pp.106.084657

Ausubel, F. M. (2005). Are innate immune signaling pathways in plants and animals conserved? Nat. Immunol. 6, 973-979. doi: 10.1038/ni1253

Bartsev, A. V., Deakin, W. J., Boukli, N. M., McAlvin, C. B., Stacey, G., Malnoe, P., et al. (2004). NopL, an effector protein of Rhizobium sp. NGR234, thwarts activation of plant defense reactions. Plant Physiol. 134, 871-879. doi: 10.1104/pp.103.031740

Boller, T., and Felix, G. (2009). A renaissance of elicitors: perception of microbe-associated molecular patterns and danger signals by pattern-recognition receptors. Annu. Rev. Plant Biol. 60, 379-406. doi: 10.1146/annurev.arplant.57.032905.105346

Broghammer, A., Krusell, L., Blaise, M., Sauer, J., Sullivan, J. T., Maolanon, N., et al. (2012). Legume receptors perceive the rhizobial lipochitin oligosaccharide signal molecules by direct binding. Proc. Natl. Acad. Sci. U.S.A. 109, 1385913864. doi: 10.1073/pnas.1205171109 can occur without NF but this requires an active T3SS. Although unidentified, the assumption is that rhizobial effector proteins are exported to the soybean host that is allowing nodulation to occur (Figure 1). The parallels to plant-pathogen interactions are clear, where effectors can either promote virulence or resistance. $\mathrm{R}$ proteins are clearly important in the rhizobial symbiosis, at least in modulating host range. At this point, the role of effectors and $\mathrm{R}$ proteins in RNS cannot be refuted. However, perhaps the more interesting question is whether these components are necessary, perhaps essential, for nodule formation either mediated by NF or not. The case in soybean cv. Enrei clearly argues for an essential role but could the research focus on NF signaling be hiding a general, essential role in RNS in other plant species?

Regardless of what form it may take, the available data clearly point to the need for more research that directly addresses the possibility of an important role for plant innate immunity in RNS. This aspect has been understudied for some time and sufficient evidence has now accumulated to strongly suggest that important information would come from such research. Using plant pathogen-host research as an example, one would expect that knowledge would emerge that could enhance the use of RNS in agriculture. For example: efforts to avoid inoculant competition with indigenous soil rhizobia that currently limits effectiveness or information that would increase nodulation under stressful environments or allow greater levels of biological nitrogen fixation.

\section{Acknowledgment}

We thank Johann Oliver Zinamon for helping with the Figure preparation. Research of the authors is supported by National Science Foundation (IOS/1025752)

Bulgarelli, D., Rott, M., Schlaeppi, K., Ver Loren van Themaat, E., Ahmadinejad, N., Assenza, F., et al. (2012). Revealing structure and assembly cues for Arabidopsis root-inhabiting bacterial microbiota. Nature 488, 91-95. doi: 10.1038/nature 11336

Cao, Y., Liang, Y., Tanaka, K., Nguyen, C. T., Jedrzejczak, R. P., Joachimiak, A., et al. (2014). The kinase LYK5 is a major chitin receptor in Arabidopsis and forms a chitin-induced complex with related kinase CERK1. Elife 3:e03766. doi: 10.7554/eLife.03766

Cardenas, L., Martinez, A., Sanchez, F., and Quinto, C. (2008). Fast, transient and specific intracellular ROS changes in living root hair cells responding to Nod factors (NFs). Plant J. 56, 802-813. doi: 10.1111/j.1365-313X.2008. 03644.x

Dai, W. J., Zeng, Y., Xie, Z. P., and Staehelin, C. (2008). Symbiosis-promoting and deleterious effects of NopT, a novel type 3 effector of Rhizobium sp. strain NGR234. J. Bacteriol. 190, 5101-5110. doi: 10.1128/JB.00306-08

Day, R. B., Okada, M., Ito, Y., Tsukada, K., Zaghouani, H., Shibuya, N., et al. (2001). Binding site for chitin oligosaccharides in the soybean plasma membrane. Plant Physiol. 126, 1162-1173. doi: 10.1104/pp.126.3.1162

De Coninck, B., Timmermans, P., Vos, C., Cammue, B. P., and Kazan, K. (2015). What lies beneath: belowground defense strategies in plants. Trends Plant Sci. 20, 91-101. doi: 10.1016/j.tplants.2014.09.007

D'Haeze, W., and Holsters, M. (2002). Nod factor structures, responses, and perception during initiation of nodule development. Glycobiology 12, 79R105R. doi: 10.1093/glycob/12.6.79R

Ding, Y., and Oldroyd G. E. (2009). Positioning the nodule, the hormone dictum. Plant Signal. Behav. 4, 89-93. doi: 10.4161/psb.4.2.7693 
Fisher, R. F., and Long, S. R. (1992). Rhizobium-plant signal exchange. Nature 357, 655-660. doi: 10.1038/357655a0

Fotiadis, C. T., Dimou, M., Georgakopoulos, D. G., Katinakis, P., and Tampakaki, A. P. (2012). Functional characterization of NopT1 and NopT2, two type III effectors of Bradyrhizobium japonicum. FEMS Microbiol. Lett. 327, 66-77. doi: 10.1111/j.1574-6968.2011.02466.x

Genre, A., Chabaud, M., Balzergue, C., Puech-Pages, V., Novero, M., Rey, T., et al. (2013). Short-chain chitin oligomers from arbuscular mycorrhizal fungi trigger nuclear $\mathrm{Ca}^{2+}$ spiking in Medicago truncatula roots and their production is enhanced by strigolactone. New Phytol. 198, 190-202. doi: 10.1111/nph.12146

Giraud, E., Moulin, L., Vallenet, D., Barbe, V., Cytryn, E., Avarre, J. C., et al. (2007). Legumes symbioses: absence of Nod genes in photosynthetic bradyrhizobia. Science 316, 1307-1312. doi: 10.1126/science.1139548

Greeff, C., Roux, M., Mundy, J., and Petersen, M. (2012). Receptor-like kinase complexes in plant innate immunity. Front. Plant Sci. 3:209. doi: 10.3389/fpls.2012.00209

Halverson, L. J., and Stacey, G. (1986). Signal exchange in plant-microbe interactions. Microbiol. Rev. 50, 193-225.

Hayashi, M., Shiro, S., Kanamori, H., Mori-Hosokawa, S., Sasaki-Yamagata, H., Sayama, T., et al. (2014). A thaumatin-like protein, Rj4, controls nodule symbiotic specificity in soybean. Plant Cell Physiol. 55, 1679-1689. doi: 10.1093/pcp/pcu099

Hubber, A., Vergunst, A. C., Sullivan, J. T., Hooykaas, P. J., and Ronson, C. W. (2004). Symbiotic phenotypes and translocated effector proteins of the Mesorhizobium loti strain R7A VirB/D4 type IV secretion system. Mol. Microbiol. 54, 561-574. doi: 10.1111/j.1365-2958.2004.04292.x

Indrasumunar, A., Kereszt, A., Searle, I., Miyagi, M., Li, D., Nguyen, C. D., et al. (2010). Inactivation of duplicated nod factor receptor 5 (NFR5) genes in recessive loss-of-function non-nodulation mutants of allotetraploid soybean (Glycine $\max$ L. Merr.). Plant Cell Physiol. 51, 201-214. doi: $10.1093 / \mathrm{pcp} / \mathrm{pcp} 178$

Indrasumunar, A., Searle, I., Lin, M. H., Kereszt, A., Men, A., Carroll, B. J., et al. (2011). Nodulation factor receptor kinase lalpha controls nodule organ number in soybean (Glycine max L. Merr). Plant J. 65, 39-50. doi: 10.1111/j.1365313X.2010.04398.x

Jones, K. M., Lloret, J., Daniele, J. R., and Walker, G. C. (2007). The type IV secretion system of Sinorhizobium meliloti strain 1021 is required for conjugation but not for intracellular symbiosis. J. Bacteriol. 189, 2133-2138. doi: 10.1128/JB.00116-06

Kambara, K., Ardissone, S., Kobayashi, H., Saad, M. M., Schumpp, O., Broughton, W. J., et al. (2009). Rhizobia utilize pathogen-like effector proteins during symbiosis. Mol. Microbiol. 71, 92-106. doi: 10.1111/j.1365-2958.2008.06507.x

Kimbrel, J. A., Thomas, W. J., Jiang, Y., Creason, A. L., Thireault, C. A., Sachs, J. L., et al. (2013). Mutualistic co-evolution of type III effector genes in Sinorhizobium fredii and Bradyrhizobium japonicum. PLoS Pathog. 9:e1003204. doi: 10.1371/journal.ppat.1003204

Kistner, C., and Parniske, M. (2002). Evolution of signal transduction in intracellular symbiosis. Trends Plant Sci. 7, 511-518. doi: 10.1016/S13601385(02)02356-7

Liang, Y., Cao, Y., Tanaka, K., Thibivilliers, S., Wan, J., Choi, J., et al. (2013). Nonlegumes respond to rhizobial Nod factors by suppressing the innate immune response. Science 341, 1384-1387. doi: 10.1126/science.1242736

Liang, Y., Toth, K., Cao, Y., Tanaka, K., Espinoza, C., and Stacey, G. (2014). Lipochitooligosaccharide recognition: an ancient story. New Phytol. 204, 289296. doi: $10.1111 /$ nph. 12898

Libault, M., Farmer, A., Brechenmacher, L., Drnevich, J., Langley, R. J., Bilgin, D. D., et al. (2010). Complete transcriptome of the soybean root hair cell, a single-cell model, and its alteration in response to Bradyrhizobium japonicum infection. Plant Physiol. 152, 541-552. doi: 10.1104/pp.109.148379

Limpens, E., Franken, C., Smit, P., Willemse, J., Bisseling, T., and Geurts, R. (2003). LysM domain receptor kinases regulating rhizobial Nod factor-induced infection. Science 302, 630-633. doi: 10.1126/science.1090074

Lundberg, D. S., Lebeis, S. L., Paredes, S. H., Yourstone, S., Gehring, J., Malfatti, S., et al. (2012). Defining the core Arabidopsis thaliana root microbiome. Nature 488, 86-90. doi: 10.1038/nature11237

Madsen, E. B., Antolin-Llovera, M., Grossmann, C., Ye, J., Vieweg, S., Broghammer, A., et al. (2011). Autophosphorylation is essential for the in vivo function of the Lotus japonicus Nod factor receptor 1 and receptor-mediated signalling in cooperation with Nod factor receptor 5. Plant J. 65, 404-417. doi: 10.1111/j.1365-313X.2010.04431.x

Madsen, E. B., Madsen, L. H., Radutoiu, S., Olbryt, M., Rakwalska, M., Szczyglowski, K., et al. (2003). A receptor kinase gene of the LysM type is involved in legume perception of rhizobial signals. Nature 425, 637-640. doi: 10.1038/nature02045

Maillet, F., Poinsot, V., Andre, O., Puech-Pages, V., Haouy, A., Gueunier, M., et al. (2011). Fungal lipochitooligosaccharide symbiotic signals in arbuscular mycorrhiza. Nature 469, 58-63. doi: 10.1038/nature09622

Martínez-Abarca, F., Herrera-Cervera, J. A., Bueno, P., Sanjuan, J., Bisseling, T., and Olivares, J. (1998). Involvement of salicylic acid in the establishment of the Rhizobium meliloti-alfalfa symbiosis. Mol. Plant Microbe Interact. 11, 153-155. doi: 10.1094/MPMI.1998.11.2.153

Millet, Y. A., Danna, C. H., Clay, N. K., Songnuan, W., Simon, M. D., WerckReichhart, D., et al. (2010). Innate immune responses activated in Arabidopsis roots by microbe-associated molecular patterns. Plant Cell 22, 973-990. doi: $10.1105 /$ tpc. 109.069658

Mitra, R. M., and Long, S. R. (2004). Plant and bacterial symbiotic mutants define three transcriptionally distinct stages in the development of the Medicago truncatula/Sinorhizobium meliloti symbiosis. Plant Physiol. 134, 595-604. doi: 10.1104/pp.103.031518

Miyata, K., Kozaki, T., Kouzai, Y., Ozawa, K., Ishii, K., Asamizu, E., et al. (2014). The bifunctional plant receptor, OsCERK1, regulates both chitin-triggered immunity and arbuscular mycorrhizal symbiosis in rice. Plant Cell Physiol. 55, 1864-1872. doi: 10.1093/pcp/pcu129

Montiel, J., Nava, N., Cardenas, L., Sanchez-Lopez, R., Arthikala, M. K., Santana, O., et al. (2012). A Phaseolus vulgaris NADPH oxidase gene is required for root infection by Rhizobia. Plant Cell Physiol. 53, 1751-1767. doi: $10.1093 / \mathrm{pcp} / \mathrm{pcs} 120$

Nguyen, T. H., Brechenmacher, L., Aldrich, J. T., Clauss, T. R., Gritsenko, M. A., Hixson, K. K., et al. (2012). Quantitative phosphoproteomic analysis of soybean root hairs inoculated with Bradyrhizobium japonicum. Mol. Cell. Proteomics 11, 1140-1155. doi: 10.1074/mcp.M112.018028

Okazaki, S., Kaneko, T., Sato, S., and Saeki, K. (2013). Hijacking of leguminous nodulation signaling by the rhizobial type III secretion system. Proc. Natl. Acad. Sci. U.S.A. 110, 17131-17136. doi: 10.1073/pnas. 1302360110

Oldroyd, G. E., and Downie, J. A. (2008). Coordinating nodule morphogenesis with rhizobial infection in legumes. Annu. Rev. Plant Biol. 59, 519-546. doi: 10.1146/annurev.arplant.59.032607.092839

Oldroyd, G. E., Murray, J. D., Poole, P. S., and Downie, J. A. (2011). The rules of engagement in the legume-rhizobial symbiosis. Annu. Rev. Genet. 45, 119-144. doi: 10.1146/annurev-genet-110410-132549

Pauly, N., Pucciariello, C., Mandon, K., Innocenti, G., Jamet, A., Baudouin, E., et al. (2006). Reactive oxygen and nitrogen species and glutathione: key players in the legume-Rhizobium symbiosis. J. Exp. Bot. 57, 1769-1776. doi: $10.1093 /$ jxb/erj184

Perret, X., Staehelin, C., and Broughton, W. J. (2000). Molecular basis of symbiotic promiscuity. Microbiol. Mol. Biol. Rev. 64, 180-201. doi: 10.1128/MMBR.64.1.180-201.2000

Pietraszewska-Bogiel, A., Lefebvre, B., Koini, M. A., Klaus-Heisen, D., Takken, F. L., Geurts, R., et al. (2013). Interaction of Medicago truncatula lysin motif receptor-like kinases, NFP and LYK3, produced in Nicotiana benthamiana induces defence-like responses. PLoS ONE 8:e65055. doi: 10.1371/journal.pone. 0065055

Radutoiu, S., Madsen, L. H., Madsen, E. B., Felle, H. H., Umehara, Y., Gronlund, M., et al. (2003). Plant recognition of symbiotic bacteria requires two LysM receptor-like kinases. Nature 425, 585-592. doi: 10.1038/nature02039

Ramu, S. K., Peng, H. M., and Cook, D. R. (2002). Nod factor induction of reactive oxygen species production is correlated with expression of the early nodulin gene rip1 in Medicago truncatula. Mol. Plant Microbe Interact. 15, 522-528. doi: 10.1094/MPMI.2002.15.6.522

Rey, T., Chatterjee, A., Buttay, M., Toulotte, J., and Schornack, S. (2015). Medicago truncatula symbiosis mutants affected in the interaction with a biotrophic root pathogen. New Phytol. 206, 497-500. doi: 10.1111/nph.13233

Rey, T., Nars, A., Bonhomme, M., Bottin, A., Huguet, S., Balzergue, S., et al. (2013). NFP, a LysM protein controlling Nod factor perception, also intervenes in Medicago truncatula resistance to pathogens. New Phytol. 198, 875-886. doi: $10.1111 / \mathrm{nph} .12198$ 
Rose, C. M., Venkateshwaran, M., Volkening, J. D., Grimsrud, P. A., Maeda, J., Bailey, D. J., et al. (2012). Rapid phosphoproteomic and transcriptomic changes in the rhizobia-legume symbiosis. Mol. Cell. Proteomics 11, 724-744. doi: 10.1074/mcp.M112.019208

Sánchez, C., Iannino, F., Deakin, W. J., Ugalde, R. A., and Lepek, V. C. (2009). Characterization of the Mesorhizobium loti MAFF303099 type-three protein secretion system. Mol. Plant Microbe Interact. 22, 519-528. doi: 10.1094/MPMI22-5-0519

Santos, R., Herouart, D., Sigaud, S., Touati, D., and Puppo, A. (2001). Oxidative burst in alfalfa-Sinorhizobium meliloti symbiotic interaction. Mol. Plant Microbe Interact. 14, 86-89. doi: 10.1094/MPMI.2001.14.1.86

Schechter, L. M., Guenther, J., Olcay, E. A., Jang, S., and Krishnan, H. B. (2010). Translocation of NopP by Sinorhizobium fredii USDA257 into Vigna unguiculata root nodules. Appl. Environ. Microbiol. 76, 3758-3761. doi: 10.1128/AEM.03122-09

Shaw, S. L., and Long, S. R. (2003). Nod factor inhibition of reactive oxygen efflux in a host legume. Plant Physiol. 132, 2196-2204. doi: 10.1104/pp.103. 021113

Soto, M. J., Sanjuan, J., and Olivares, J. (2006). Rhizobia and plant-pathogenic bacteria: common infection weapons. Microbiology 152(Pt 11), 3167-3174. doi: 10.1099/mic. 0.29112-0

Stacey, G., McAlvin, C. B., Kim, S. Y., Olivares, J., and Soto, M. J. (2006). Effects of endogenous salicylic acid on nodulation in the model legumes Lotus japonicus and Medicago truncatula. Plant Physiol. 141, 1473-1481. doi: 10.1104/pp.106.080986

Tang, F., Yang, S. M., Liu, J. E., Gao, M. Q., and Zhu, H. Y. (2014). Fine mapping of the Rj4 locus, a gene controlling nodulation specificity in soybean. Mol. Breed. 33, 691-700. doi: 10.1007/s11032-013-9985-y

Tsukui, T., Eda, S., Kaneko, T., Sato, S., Okazaki, S., Kakizaki-Chiba, K., et al. (2013). The type III secretion system of Bradyrhizobium japonicum USDA122 mediates symbiotic incompatibility with Rj2 soybean plants. Appl. Environ. Microbiol. 79, 1048-1051. doi: 10.1128/AEM.03297-12

Vasse, J., de Billy, F., and Truchet, G. (1993). Abortion of infection during the Rhizobium meliloti-alfalfa symbiotic interaction is accompanied by a hypersensitive reaction. Plant J. 4, 555-566. doi: 10.1046/j.1365313X.1993.04030555.x

Wenzel, M., Friedrich, L., Gottfert, M., and Zehner, S. (2010). The type III-secreted protein NopE1 affects symbiosis and exhibits a calcium-dependent autocleavage activity. Mol. Plant Microbe Interact. 23, 124-129. doi: 10.1094/MPMI-23-10124

Xin, D. W., Liao, S., Xie, Z. P., Hann, D. R., Steinle, L., Boller, T., et al. (2012). Functional analysis of NopM, a novel E3 ubiquitin ligase (NEL) domain effector of Rhizobium sp. strain NGR234. PLoS Pathog 8:e1002707. doi: 10.1371/journal.ppat.1002707

Yang, S., Tang, F., Gao, M., Krishnan, H. B., and Zhu, H. (2010). R gene-controlled host specificity in the legume-rhizobia symbiosis. Proc. Natl. Acad. Sci. U.S.A. 107, 18735-18740. doi: 10.1073/pnas.1011957107

Zhang, L., Chen, X. J., Lu, H. B., Xie, Z. P., and Staehelin, C. (2011). Functional analysis of the type 3 effector nodulation outer protein L (NopL) from Rhizobium sp. NGR234: symbiotic effects, phosphorylation, and interference with mitogen-activated protein kinase signaling. J. Biol. Chem. 286, 3217832187. doi: 10.1074/jbc.M111.265942

Zhang, X., Dong, W., Sun, J., Feng, F., Deng, Y., He, Z., et al. (2015). The receptor kinase CERK1 has dual functions in symbiosis and immunity signalling. Plant J. 81, 258-267. doi: 10.1111/tpj.12723

Zipfel, C. (2014). Plant pattern-recognition receptors. Trends Immunol. 35, 345351. doi: 10.1016/j.it.2014.05.004

Conflict of Interest Statement: The authors declare that the research was conducted in the absence of any commercial or financial relationships that could be construed as a potential conflict of interest.

Copyright (c) 2015 Tóth and Stacey. This is an open-access article distributed under the terms of the Creative Commons Attribution License (CC BY). The use, distribution or reproduction in other forums is permitted, provided the original author(s) or licensor are credited and that the original publication in this journal is cited, in accordance with accepted academic practice. No use, distribution or reproduction is permitted which does not comply with these terms. 